\title{
ANAESTHESIA FOR EVALUATION AND EXCISION OF TRACHEAL TUMOUR AT CARINA EXTENDING INTO RIGHT MAIN BRONCHUS: CASE REPORT
}

\author{
Deepraj Singh B1 ${ }^{1}$ Raghuram C. $\mathrm{G}^{2}$, Geetha $\mathrm{C}^{3}$, Amisha $\mathrm{K}^{4}$
}

\section{HOW TO CITE THIS ARTICLE:}

Deepraj Singh B, Raghuram C. G, Geetha C, Amisha K. "Anesthesia for Evaluation and Excision of Tracheal Tumor at Carina Extending into Right main Bronchus: Case Report". Journal of Evolution of Medical and Dental Sciences 2014; Vol. 3, Issue 16, April 21; Page: 4418-4423, DOI: 10.14260/jemds/2014/2452

ABSTRACT: A tracheal tumor at carinal angle is uncommon. Presented here is an interesting case of a 22 year old, HBsAg positive female with a tracheal tumor at carina extending into the right main bronchus. The patient reported shortness of breath along with fatigue and cough. Routine and other appropriate investigations were done during which X-ray chest and CT scan revealed right lung collapse with ipsilateral shift of mediastinum. Telescopic evaluation and biopsy performed under general anesthesia using supraglottic Jet Ventilation further revealed proliferative growth arising from the anterior wall of the carina extending into the right main bronchus. Subsequently, excision of the tumor through tracheotomy under general anesthesia was carried out. The patient recovered completely with no postoperative complications.

KEYWORDS: Tracheal tumor, supraglottic jet ventilation, tracheotomy.

INTRODUCTION: Tracheal tumor located at carina extending into right main bronchus for evaluation, biopsy and excision poses a challenge to the anesthesiologist and to the surgeon equally. Difficulty can be faced during induction, intubation, maintenance, and recovery of the patient. Ventilating the patient and maintaining the required oxygen saturation is not easy. Bleeding during the excision and risk of aspiration of blood are the other major associated risks. Sharing the surgical field with the surgeon makes it all the more difficult.

CASE REPORT: A 22 year old female weighing $31 \mathrm{kgs}$ came with complaints of shortness of breath along with cough since 4 months. The patient was asymptomatic 4 months back and stated she gradually developed breathlessness. She initially complained of breathlessness while walking but later experienced the same symptoms even during sitting or lying down. This was aggravated while lying on the left side. There was no history of chest pain, palpitation, paroxysmal nocturnal dyspnea and pedal edema. The cough was initially dry which later was of productive type. Expectorant was mucoid in nature but neither copious nor blood stained. Cough was also not related to posture. There was no history of fever or weight loss. There were no similar complaints in the past. She had neither history of pulmonary tuberculosis nor relevant family history. She was symptomatically treated and experienced only slight relief of symptoms.

Patient was thin built, comfortable while in sitting position_breathless on lying down in left lateral position. There was no pallor, lymphadenopathy, clubbing, pedal edema, or cyanosis. The patients' vitals were pulse rate 86/min, rhythm regular, volume good, blood pressure 90/70 $\mathrm{mmHg}$, respiratory rate $18 / \mathrm{min}$, temperature normal.

Respiratory system - during inspection it was found that trachea was displaced to the right, chest movement on the right side diminished during respiration. On percussion, a dull note was elicited on 
the right side of the chest while the left side was resonant. On auscultation no air entry on right side of chest , air entry present on left side with coarse crepitaions.

Cardio Vascular system examination revealed apical beat shifted towards the right side-_heart sound normal, no murmur.

Central nervous system was normal, abdomen soft, liver and spleen not palpable.

Airway assessment - mouth opening was normal, Mallampatti grade 1.

Investigations - routine investigations were within normal limits, HBsAg positive, chest CT scan and X-ray revealed right lung collapse with ipsilateral shift of mediastinum.

Patient was posted for bronchoscopic/telescopic evaluation under general anesthesia.

Patient was positioned supine on the table as she was comfortable lying supine. All precautions were taken by the medical and para-medical personnel as the patient was $\mathrm{HBsAg}$ positive. Requisite monitors were connected, pulse oximeter showed $\mathrm{SpO}_{2} 94 \%$, BP was 90/60 mm $\mathrm{Hg}$, PR $80 / \mathrm{min}$ and intravenous line secured. Patient was pre-oxygenated with $100 \% \mathrm{O}_{2}$ for 3 mins, pre-medicated with Glycopyrrolate_0.2mg,ondansetron $4 \mathrm{mg}$,induced with propofol $60 \mathrm{~m}$ with short acting muscle relaxant suxamethonium $50 \mathrm{mg}$ used to see if ventilation was easy with mask. Once it was confirmed that ventilation was no problem, vitals were stable, oxygen saturation maintained at 100 percent long acting muscle relaxant atracurium was given for maintainance with desflurane.

Larynx was exposed by laryngoscopy while the surgeon introduced the telescope which was connected to monitor through 3 chip camera. Ventilation was maintained by supraglottic jet ventilation. There was no chest lift on right side while on the left side it was normal. On auscultation there was no air entry on the right side of chest and on left side air entry was good. $\mathrm{SpO}_{2}$ was maintained between $96 \%-98 \%$.

Telescopic finding revealed proliferating growth (figure 1) firm in consistency arising from the anterior wall of the carina extending into the right main bronchus blocking the right main bronchus completely, the opening to the left main bronchus was free and clearly visible. Biopsy was taken and sent for histopathology. Adrenaline was applied and hemostasis was secured. Vitals were stable throughout the procedure. Patient was reversed with Neostigmine 2.5mgs and Glycopyrrolate $0.4 \mathrm{mg}$. Recovery was smooth and uneventful. Four days later report of HPE revealed benign spindle cells lesion - fibro inflammatory reaction.-a benign tumor.

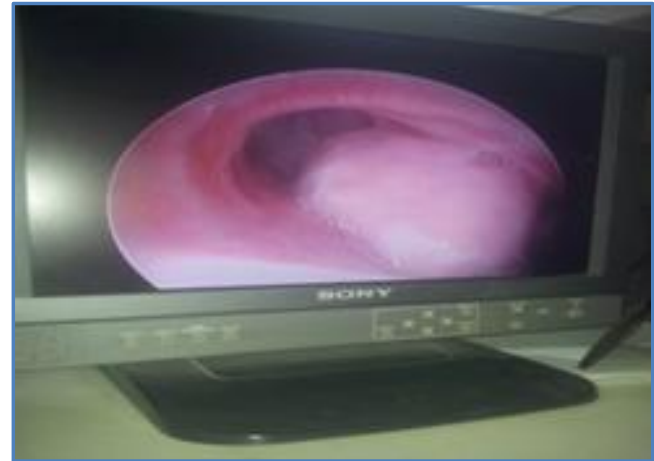

Fig. 1: Tumour during evaluation through

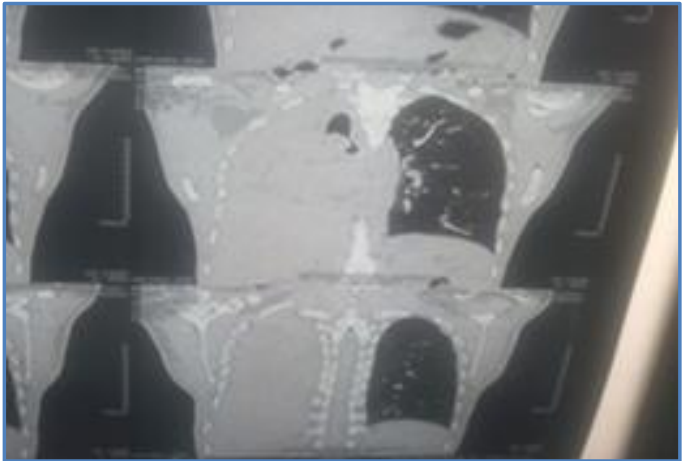

Fig. 2: CT Scan showing right lung collapse and tumour 
Going by the telescopic findings plan was to intubate with small size endotracheal tube so that in case of airway compromise by tumor itself or bleeding during excision the same endotracheal tube can be advanced into left main bronchus, cuff inflated and one lung ventilation done, Surgical excision of the tumor was planned to be executed through tracheotomy(Figure 3). Patient was posted for tracheal tumor excision 10 days later. Patient was positioned supine on the table and all necessary precautions were taken as the patient was HBsAg positive. Monitors were attached, pulse oximeter showed $\mathrm{SpO}_{2} 94 \%$, BP 90/60 mm $\mathrm{Hg}$, PR 80/min while IV line was secured. Patient was preoxygenated with $100 \% \mathrm{O}_{2}$ for 3 mins, pre-medicated with Glycopyrrolate, Ondansetron and was induced with Thiopentone Sodium.

Muscle relaxant Suxamethonium was used and endotracheal intubation with 5.0 MLS endotracheal tube done and was positioned at subglottic region. The cuff was inflated and tube secured. Intubation was easy; patient was maintained on 2 liters $\mathrm{O}_{2}$ and 2 liters of $\mathrm{N}_{2} \mathrm{O}$, Desflurane 3\%, and muscle relaxant Atracurium. On auscultation, air entry was absent on the right side and present on the left side. Trachea was opened in front of the neck at the level of 3 and 4 tracheal rings. Through tracheotomy telescope was introduced. Proliferative growth (figure 4) was identified at the carina which was encroaching the right bronchus.

The tumor was excised in total with the help of good cautery and efficient suctioning (Figure 5) which minimized bleeding. After excision of the tracheal tumor right main bronchus which was obstructed before surgery was now clearly visible including the segmental bronchi (figure 6).Tracheotomy incision was closed (Figure 7), the entire procedure lasted for 1 hour 15 mins. After the surgical procedure, the chest lift and air entry improved on the right side.

Vitals were stable throughout the procedure. $\mathrm{SpO}_{2}$ maintained at $95 \%-99 \%$. After the surgical procedure, patient ventilated with high flows and increased pressures to inflate the collapsed right lung. Reversal of patient was done using Neostigmine and Glycopyrrolate. Patient extubated, recovery was smooth and the patient was conscious, coherent.

Bilateral air entry was present, air entry of the right lung improved dramatically. Postoperative vitals were normal.

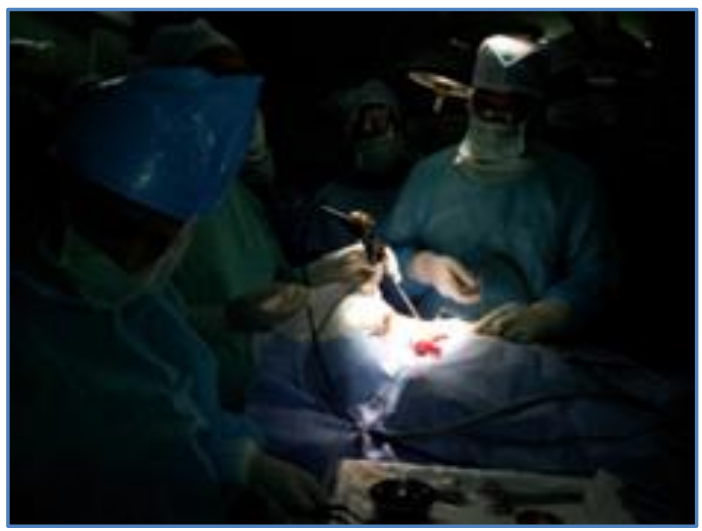

Fig. 3: Instrumentation through tracheotomy

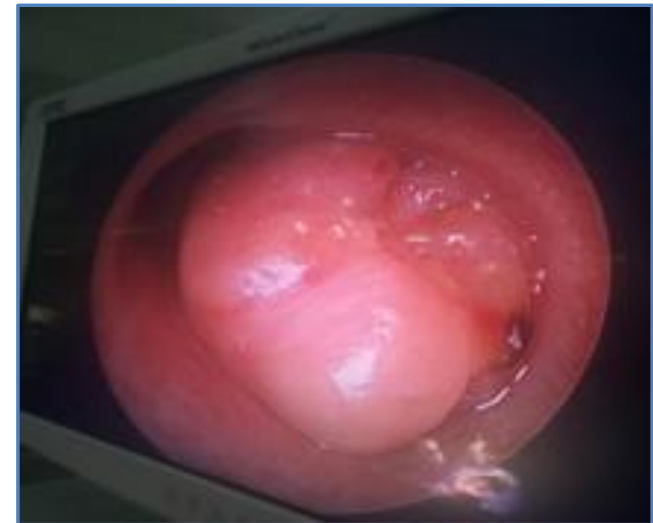

Fig. 4: Tumour as viewed through telescope 


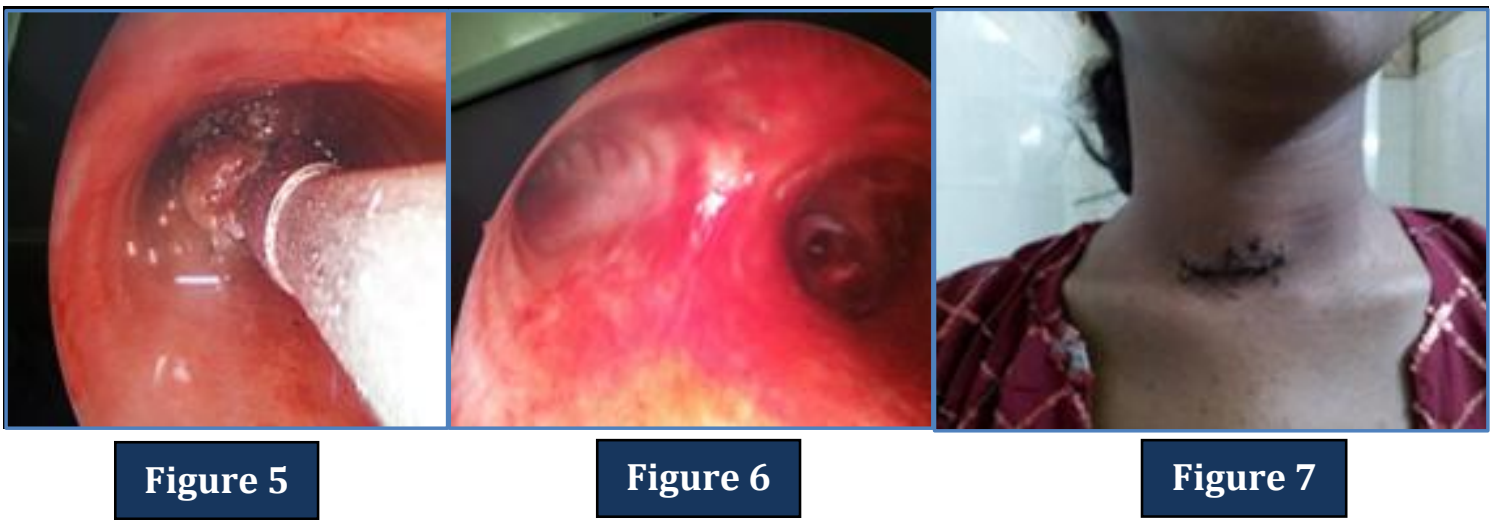

Tracheal tumour before and after excision as visualized through telescope

DISCUSSION: Tracheal tumor at the carina with extension into right main bronchus is difficult to approach and excise for the surgeon. Left endobronchial intubation was not planned initially as the tube would hinder and obscure the surgeon's view. This situation would prove to be difficult to introduce the endoscope. Secondly there was the possibility that a blind attempt at left endobronchial intubation may disrupt the tumor and may initiate severe bleeding after which the situation may become more critical.

The plan was to intubate orally and after tracheotomy was performed, depending upon the ability to ventilate the patient and maintain saturation levels, decide whether to continue with oral endotracheal tube or introduce through the tracheotomy and maneuver the tube into the left bronchus under telescopic guidance if needed. Since saturations were being maintained and patient could be ventilated satisfactorily, it was decided to continue to ventilate through the oral ETT.

If a situation arose because of dropping oxygen saturation, left endobronchial intubation would have been performed but it would have been difficult to perform the surgery. This is because instruments such as telescope, cautery, suction, scissors, and forceps along with the ETT would all have to be introduced through the tracheotomy. This situation however did not arise.

The other associated complexity faced was ventilating the patient because of the leak of gases through the tracheotomy. High flows were used to overcome this leak to some extent. Even with this leak, saturations were maintained between $97 \%$ - 99\%. It was hence decided to go ahead with oral ETT for maintenance of anesthesia.

The associated risk of bleeding and aspiration was overcome with efficient cautery, suctioning and precision of surgery which resulted in minimal bleeding. It was also necessary to expand the collapsed right lung after the excision of the tumor. This task was efficiently done by increasing the pressures and $\mathrm{O}_{2}$ flush. This improved the air entry into the right lung.

The outcome of such a complex surgery was excellent and no anesthesia or surgical related complications arose. The patient recovered completely and was totally symptom free. Biopsy report of the tumour confirmed inflammatory myofibroblastic tumour of trachea.

Satoh M, Hirabayashi Y and Seo N1,Garg SK, Tiwari RL, Garg MK, Chaturvedi S2 reported a patient of large tracheal tumor at the carina that caused severe respiratory distress .Intravenous 
anesthesia with propofol, spontaneous breathing through a tracheal tube and high frequency jet ventilation were successfully employed during bronchoscopic resection of tumor. In another study Deepa Kane, Sona Dave, Raghu S Thota, Prasant Pawar, LV Dewoolkar ${ }^{3}$ presented a case of tracheal tumour involving the lower end of trachea extending into right bronchus one lung ventilation during resection was maintained by selective left bronchial intubation under vision.

Many studies 4, 5 done on successful resection of trachea and segment of bronchus using temporary cardiopulmonary bypass and isolated lung ventilation for tracheal stenosis and reconstruction.

CONCLUSION: We present this case to stress the importance of planning and execution of excision of tracheal tumor by both anesthesiologist and ENT and head and neck surgeon. The complication expected in this case was hypoxia especially if the tumour would have bled compromising ventilation and surgical approach to excise the tumour.

The plan to ventilate the patient through oral introduction of endotracheal intubation with small MLS tube which could be passed beyond the tumour into left main bronchus in case of compromising the airway and ventilation leading to fall in oxygen saturation. Surgical approach to excision of the tumour was planned through tracheotomy for telescopy and instrumentation .The report provides the clinician an insight to approach a similar patient with carinal tumour of trachea for safe patient care.

\section{REFERENCES:}

1. Satoh M, Hirabayashi Y, Seo N. Spontaneous breathing combined with high frequency jet ventilation during bronchoscopic resection of large tracheal tumour. Br J Anaes. 2002, 89: 6413.

2. Garg SK, Tiwari RL, Garg MK, Chaturvedi S. Anesthetic management for successful removal of intratracheal tumor. Ann Card Anaesth 2011; 14: 232-5

3. Deepa Kane, Sona Dave, Raghu S Thota, Prasant Pawar, LV Dewoolkar. Tracheal Tumour Resection - Anaesthetic Management. Bombay Hospital Journal, Vol. 50, No. 1, 2008

4. Bhate JJ, Deepthi NV, Menon UK, Madhumita K. Rare Benign Tracheal Lesions. Int J Phonosurg Laryngol 2012;2 (1):37-40

5. Chni C L, Tch BJ, Wang CY. Temporary CBP and isolated lung ventilation for tracheal stenosis and reconstruction. Br J Anaes. 2003, 91(5), 742-44. 


\section{AUTHORS:}

1. Deepraj Singh B.

2. Raghuram C. G.

3. Geetha $\mathrm{C}$.

4. Amisha K.

\section{PARTICULARS OF CONTRIBUTORS:}

1. Professor, Department of Anaesthesiology, Osmania Medical College, Hyderabad, A. P.

2. Professor and HOD, Department of Anaesthesiology, Osmania Medical College, Hyderabad, A. P.

3. Assistant Professor, Department of Anaesthesiology, Osmania Medical College, Hyderabad, A. P.
4. Senior Resident, Department of Anaesthesiology, Osmania Medical College, Hyderabad, A. P.

\section{NAME ADDRESS EMAIL ID OF THE CORRESPONDING AUTHOR:}

Dr. Deepraj Singh B,

\#1-7-145/15,

Opposite Usha Mayrui Talkies,

Musheerabad,

Hyderabad- 500020, A. P.

E-mail: drdeepraj@gmail.com

Date of Submission: 24/03/2014.

Date of Peer Review: 25/03/2014.

Date of Acceptance: 04/04/2014.

Date of Publishing: 21/04/2014. 